\title{
Effects of Au Nanoparticle Addition to Hole Transfer Layer in Organic Photovoltaic Cells Based on Phthalocyanines and Fullerene
}

\author{
Akihiko Nagata, ${ }^{1}$ Takeo Oku, ${ }^{1}$ Tsuyoshi Akiyama, ${ }^{1}$ Atsushi Suzuki, ${ }^{1}$ \\ Yasuhiro Yamasaki, ${ }^{2}$ and Tomohiro Mori ${ }^{2}$ \\ ${ }^{1}$ Department of Materials Science, School of Engineering, The University of Shiga Prefecture, 2500 Hassaka, Hikone, \\ Shiga 522-8533, Japan \\ ${ }^{2}$ Department of New Business, Orient Chemical Industries Co., Ltd., 8-1 Sanra-Higashi-machi, Neyagawa, Osaka 572-8581, Japan
}

Correspondence should be addressed to Takeo Oku, oku@mat.usp.ac.jp

Received 14 February 2011; Revised 12 August 2011; Accepted 7 September 2011

Academic Editor: Guifu Zou

Copyright (C) 2011 Akihiko Nagata et al. This is an open access article distributed under the Creative Commons Attribution License, which permits unrestricted use, distribution, and reproduction in any medium, provided the original work is properly cited.

\begin{abstract}
Phthalocyanines/fullerene organic photovoltaic cells were fabricated and characterized. Effects of Au nanoparticle addition to a hole transfer layer were also investigated, and power conversion efficiencies of the photovoltaic cells were improved after blending the Au nanoparticle into PEDOT:PSS. Nanostructures of the Au nanoparticles were investigated by transmission electron microscopy and X-ray diffraction. Energy levels of molecules were calculated by molecular orbital calculations, and the nanostructures and electronic property were discussed.
\end{abstract}

\section{Introduction}

In noble metal particles such as gold or silver from tens of nanometer to several nanometers, the vibrational frequency of localized surface plasmon resonates with a photoelectric field of the wavelength of the visible region [1-4]. When visible light is irradiated to noble metal nanoparticles or nanostructures, light is converted into surface plasmon and the localized electric field generated in the vicinity of surface of nanoparticles or nanostructures. The plasmon electric filed is excited dye molecules as well as light, and interesting phenomena and various applications have been reported [5-8]. In addition, the group velocity of light decreases in such nanospace and the photoabsorption efficiency of dye arranged in the nanospace would be reinforced. Therefore, clarifications and applications of the reinforcement mechanism are interesting research objects.

Phthalocyanines have been widely studied as attractive materials for photovoltaic, electrochemical, gas-sensing, and data-storage devices $[9,10]$. Phthalocyanine molecules have planar unit and electronic conductivity because of the $\pi$ electron system and have p-type semiconductor behavior [11]. Therefore, they have been investigated as thin film organic photovoltaic cells, which are expected as nextgeneration photovoltaic cells because of advantages of easy manufacture process, low production cost, and flexibility [12-14]. The photovoltaic devices consisting of noble metal nanostructures or nanoparticles with the localized electric field have been reported $[15,16]$. However, there are few studies on organic photovoltaic cells with noble metal nanostructures or nanoparticles.

The purpose of the present work is to fabricate and characterize organic photovoltaic cells based on phthalocyanines and fullerene $\left(\mathrm{C}_{60}\right)$. In the present work, $\mathrm{C}_{60}$ was used as n-type semiconductor, and copper naphthalocyanine $(\mathrm{CuNc})$ and subphthalocyanine (SubPc) were used as ptype semiconductors, respectively. In addition, effects of $\mathrm{Au}$ nanoparticle (AuNP) addition to a hole transfer layer were investigated. For metal nanoparticles such as $\mathrm{Au}$ and Ag, strongly enhanced electric fields are locally generated in their nanospaces by irradiation of light. This phenomenon is due to localized surface plasmon resonance (LSPR), which is 
expected to enhance light harvesting of the organic solar cells [15-19]. Photovoltaic devices were fabricated, and nanostructures, electronic property, and optical absorption were investigated.

\section{Experimental Procedures}

Aqueous stock solution of $\mathrm{HAuCl}_{4}\left(2.5 \times 10^{-4} \mathrm{M}\right)$ was prepared and refluxed. After reflux for $40 \mathrm{~min}$, $1 \mathrm{wt} . \%$ sodium citrate of $1.4 \mathrm{~mL}$ was added to reaction mixture. After reflux for $60 \mathrm{~min}$, it was cooled under the air atmosphere. The fabricated AuNP solution was concentrated by the centrifugation. To prepare the composite buffer layer, the concentrated AuNP solution was blended into the polyethylenedioxythiophene doped with polystyrene sulfonic acid (PEDOT:PSS, Sigma-Aldrich Corp.) solution. The volume ratio of AuNP solution was 20\%.

A buffer layer of PEDOT:PSS with AuNPs was spin coated on precleaned indium tin oxide (ITO) glass plates (Geomatec Co. Ltd., $\sim 10 \Omega / \square)$. After annealing at $100^{\circ} \mathrm{C}$ for $10 \mathrm{~min}$ in $\mathrm{N}_{2}$ atmosphere, $\mathrm{p}$-type photoactive layers were prepared on a PEDOT layer. Copper (II) 2,3-naphthalocyanine (CuNc, Sigma-Aldrich Corp., 85\%) layers were deposited by a spin coating method, and subphthalocyanine (SubPc, Orient Chemical Industries Co., Ltd.) layers were deposited by evaporation, respectively. After depositing p-type photoactive layers, $\mathrm{C}_{60}$ thin films were deposited using $\mathrm{C}_{60}$ powder (Material Technologies Research Ltd., 99.98\%) by a vacuum deposition method. Aluminum ( $\mathrm{Al})$ metal contacts with a thickness of $100 \mathrm{~nm}$ were evaporated as a top electrode. A schematic diagram of the present photovoltaic cells is shown in Figure 1.

The current density-voltage $(J-V)$ characteristics (Hokuto Denko Co. Ltd., HSV-110) of the photovoltaic cells were measured both in the dark and under illumination at $100 \mathrm{~mW} \mathrm{~cm}^{-2}$ by using an AM 1.5 solar simulator (San-ei Electric Co. Ltd., XES-301S). The photovoltaic cells were illuminated through the side of the ITO substrates, and the illuminated area is $0.16 \mathrm{~cm}^{2}$. Incident photon to current conversion efficiency (IPCE) was measured by using hypermonolight (Bunkoukeiki Co. Ltd., SM-25) and potentiostat (Huso Ltd., HECS 318C). The photovoltaic cells were irradiated by monochromated Xe lamp from the ITO side. Absorption spectra were measured by means of UVvisible spectroscopy (JASCO, V-670), and the wavelength region is in the range of $300 \mathrm{~nm} \sim 800 \mathrm{~nm}$. Microstructures of AuNPs were analyzed using X-ray diffractometer (Philips X' Pert-MPD System) with $\mathrm{CuK} \alpha$ radiation operating at $40 \mathrm{kV}$ and $40 \mathrm{~mA}$. Transmission electron microscope (TEM) observation was carried out by a $200 \mathrm{kV}$ TEM (Hitachi, H-8100).

The isolated molecular structures were optimized by $a b$ initio molecular orbital calculations using Gaussian 03. Conditions in the present calculation were as follows: calculation type (SP), calculation method (B3LYP), and basis set (LANL2DZ). Electronic structures such as energy gaps between highest occupied molecular orbital (HOMO) and lowest unoccupied molecular orbital (LUMO), and electron densities were investigated.

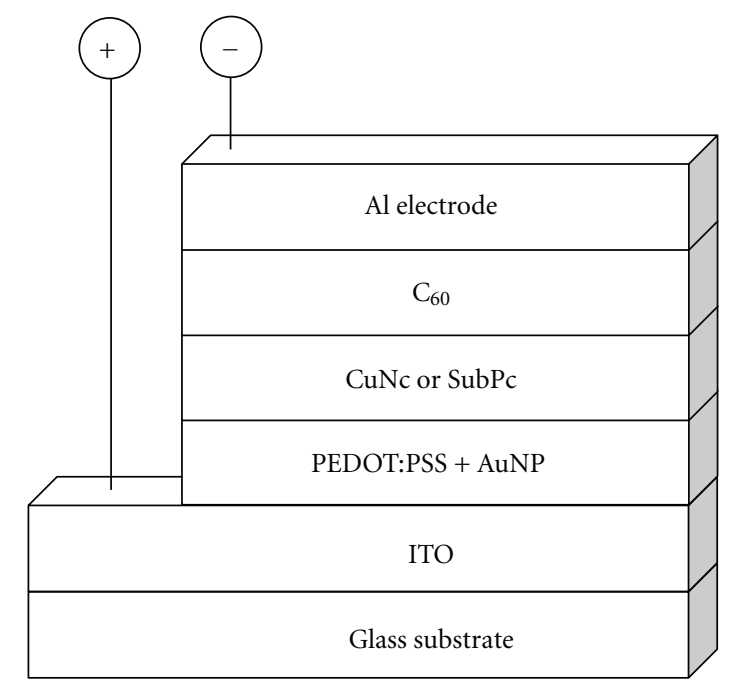

Figure 1: Schematic diagram of the present photovoltaic cells.

\section{Results and Discussion}

A TEM image and an electron diffraction pattern of AuNP are shown in Figures 2(a) and 2(b), respectively. AuNPs have an fcc structure with a lattice parameter of $a=0.40786 \mathrm{~nm}$. In the TEM image of Figure 2(a), AuNPs have a spherical shape and grain sizes of AuNPs were in the range of $40 \sim$ $60 \mathrm{~nm}$. An X-ray diffraction pattern of the AuNPs sample prepared by the present reduction method is shown in Figure 3. From a 111 diffraction peak, a grain size was calculated by using Debye-Scherrer formula: $D=0.9 \lambda / \beta \cos \theta$, where $\lambda, \beta$, and $\theta$ represent the wavelength of X-ray source, the full width at half maximum (FWHM), and the Bragg angle, respectively. An average particle size is calculated to be $42 \mathrm{~nm}$, which agrees well with the observed TEM data as shown in Figure 2(a).

Figure 4 shows absorption spectra of AuNP solution and AuNPs in PEDOT:PSS deposited by a spin coating method on glass substrates. In Figure 4, absorption peaks were confirmed to be 536 and $578 \mathrm{~nm}$, respectively, which were originated from plasmon absorption.

Optical absorption spectra of $\mathrm{CuNc} / \mathrm{C}_{60}$ and $\mathrm{SubPc} / \mathrm{C}_{60}$ thin film on glass substrate are shown in Figures 5(a) and 5(b), respectively. In Figure 5(a), absorption peaks at $350 \mathrm{~nm}$ and $450 \mathrm{~nm}$ are due to $\mathrm{C}_{60}$ and other peaks are due to CuNc. In Figure 5(b), an absorption peak at $580 \mathrm{~nm}$ is due to SubPc. The present $\mathrm{CuNc} / \mathrm{C}_{60}$ and $\mathrm{SubPc} / \mathrm{C}_{60}$ heterojunction structures with AuNPs provided absorbance increase for the wavelength from $500 \mathrm{~nm}$ to $700 \mathrm{~nm}$.

Measured $J-V$ characteristics of $\mathrm{CuNc} / \mathrm{C}_{60}$ and SubPc/ $\mathrm{C}_{60}$ photovoltaic cells with or without AuNP under illumination are shown in Figure 6. The present structures show characteristic curve for open-circuit voltage and short-circuit current. Measured parameters of the present photovoltaic cells are summarized in Table 1 . In Table $1, \mathrm{CuNc}_{\mathrm{C}} / \mathrm{C}_{60}$ and SubPc/ $\mathrm{C}_{60}$ heterojunction structures with AuNPs provided higher short-circuit current compared to those of $\mathrm{CuNc} / \mathrm{C}_{60}$ and $\mathrm{SubPc} / \mathrm{C}_{60}$ structures without AuNP. The $\mathrm{SubPc} / \mathrm{C}_{60}$ 


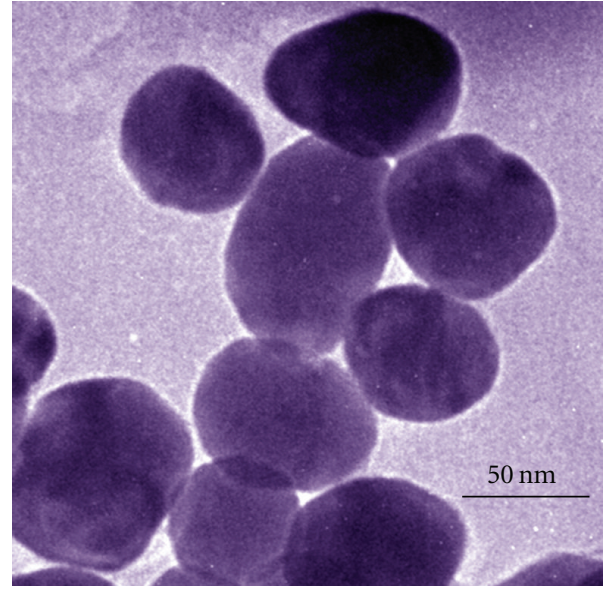

(a)

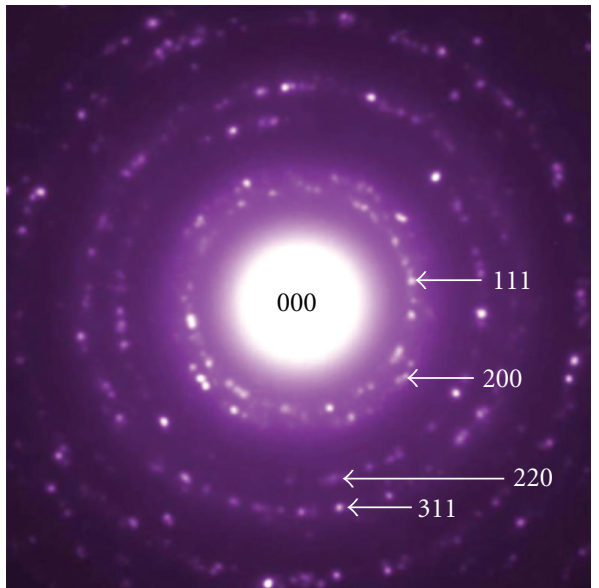

(b)

FIGURE 2: (a) TEM image and (b) electron diffraction pattern of AuNPs.

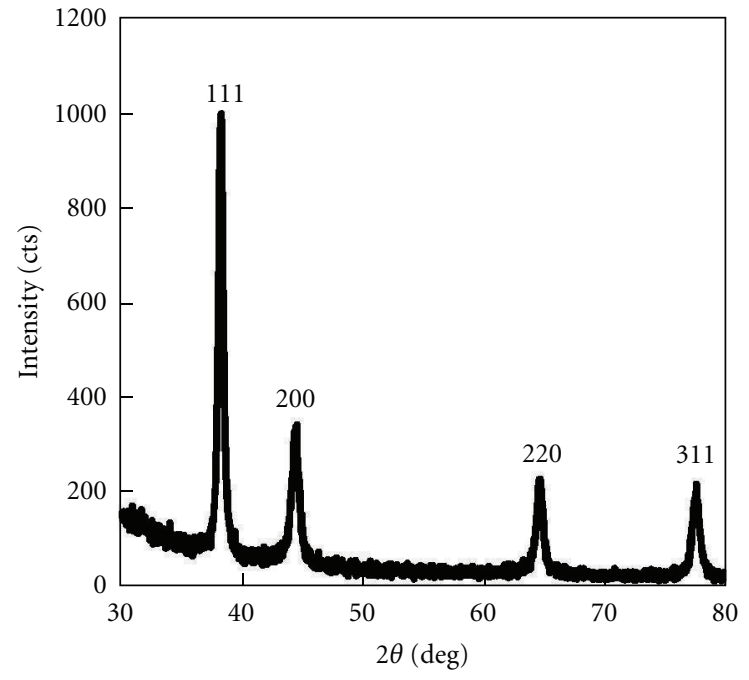

Figure 3: X-ray diffraction pattern of AuNPs.

heterojunction structure with AuNPs provided short-circuit current $\left(J_{\mathrm{sc}}\right)$ of $0.44 \mathrm{~mA} \mathrm{~cm}^{-2}$, open-circuit voltage $\left(V_{\mathrm{oc}}\right)$ of $0.55 \mathrm{~V}$, fill factor $(\mathrm{FF})$ of 0.28 , and power conversion efficiency $(\eta)$ of $0.068 \%$, respectively.

Figure 7 shows the incident photon to current conversion efficiency (IPCE) spectra of $\mathrm{SubPc} / \mathrm{C}_{60}$ photovoltaic cells with or without AuNP. The photovoltaic cells with AuNPs demonstrated the high IPCE spectrum in the range of 500 $600 \mathrm{~nm}$, which corresponded well with the absorption peak of AuNPs as observed in Figure 4.

Electronic structures, HOMOs, LUMOs, and energy gaps of $\mathrm{CuNc}$ and SubPc are shown in Figure 8. HOMO and LUMO of CuNc were calculated to be $-3.13 \mathrm{eV}$ and $-5.01 \mathrm{eV}$, respectively, on the basis of molecular orbital calculation. HOMO and LUMO of SubPc were calculated to be $-3.02 \mathrm{eV}$ and $-5.74 \mathrm{eV}$, respectively.

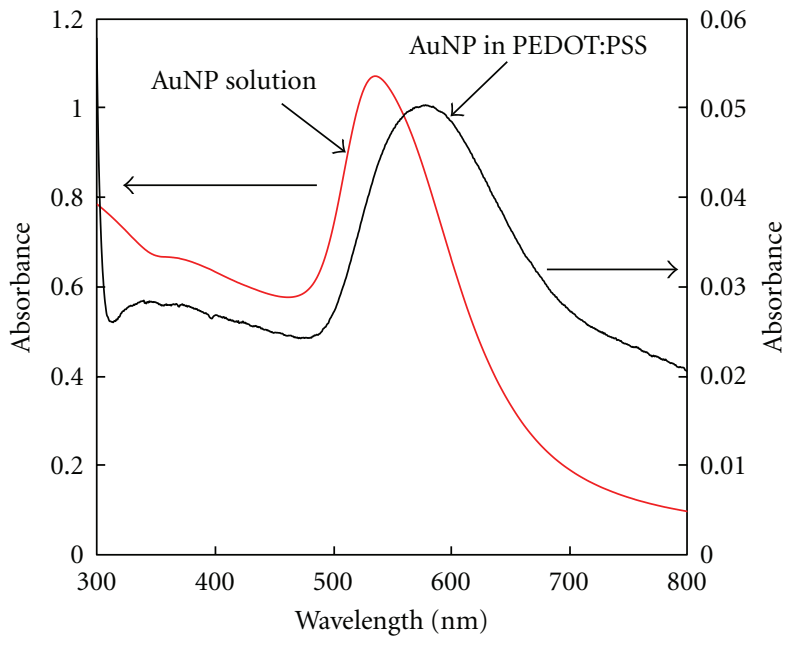

FIgURE 4: Absorption spectra of AuNP solution and AuNP in PEDOT:PSS.

An energy level diagram of the present photovoltaic cells is summarized as shown in Figure 9. Previously reported values were also used for the energy levels [20-22]. The carrier transport mechanism is considered as follows. When light is incident from the ITO substrate, light-absorption excitation occurs at the $\mathrm{Pcs} / \mathrm{C}_{60}$ interface and electrons and holes are produced by charge separation. Then, the electrons transport through $\mathrm{C}_{60}$ toward the $\mathrm{Al}$ electrode, and the holes transport through PEDOT:PSS to the ITO substrate. Since it has been reported that $V_{\mathrm{oc}}$ is nearly proportional to the difference between HOMO of electronic donor (Pcs) and LUMO of electronic accepter $\left(\mathrm{C}_{60}\right)$ [23], the difference of $V_{\mathrm{oc}}$ would be considered to be the combination of Pcs and $\mathrm{C}_{60}$.

In the present work, organic photovoltaic cells with AuNPs based on phthalocyanines and $\mathrm{C}_{60}$ were fabricated and characterized. Performance of the present photovoltaic 


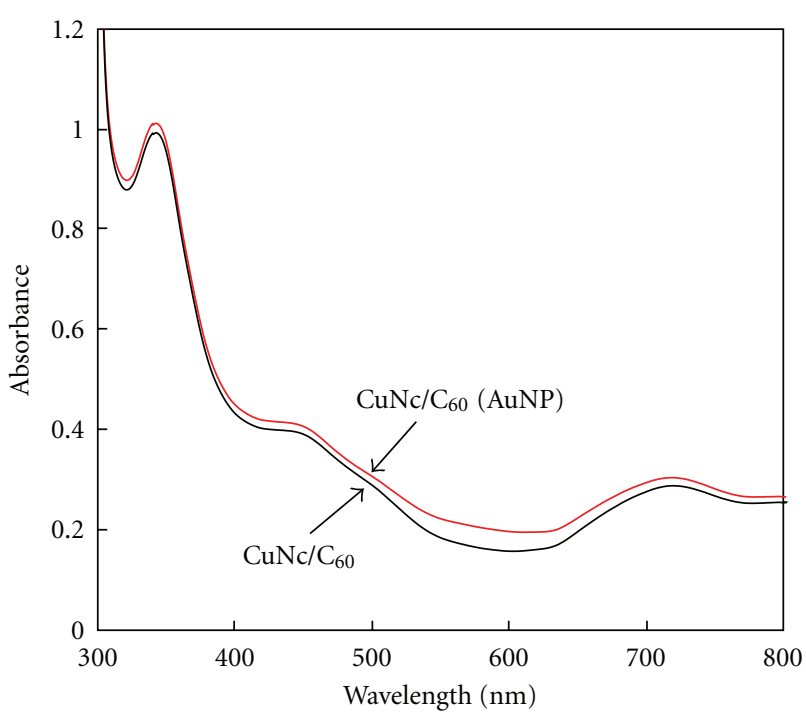

(a)

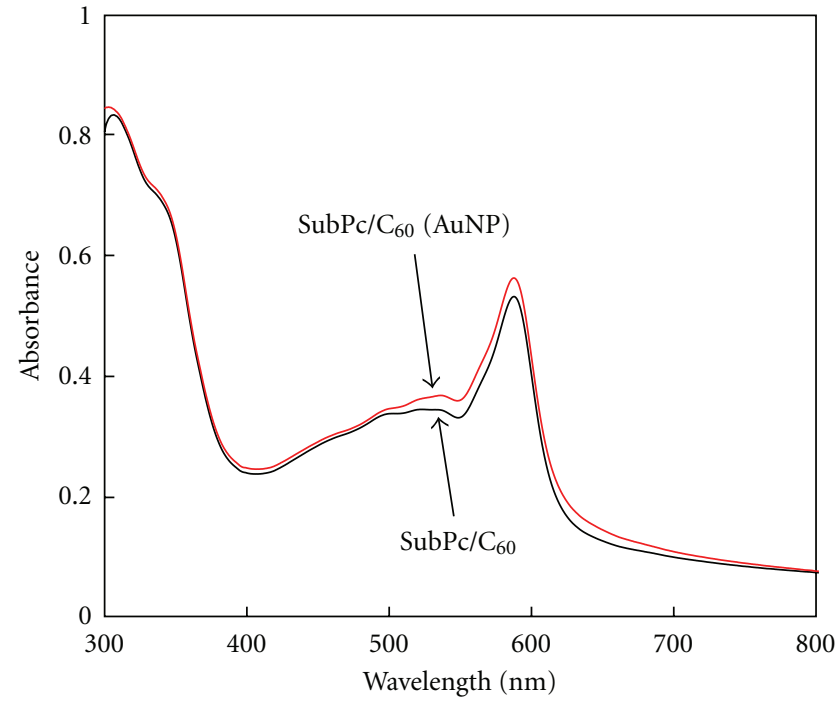

(b)

Figure 5: Absorption spectra of (a) $\mathrm{CuNc} / \mathrm{C}_{60}$ and (b) $\mathrm{SubPc}_{\mathrm{C}} \mathrm{C}_{60}$ films.

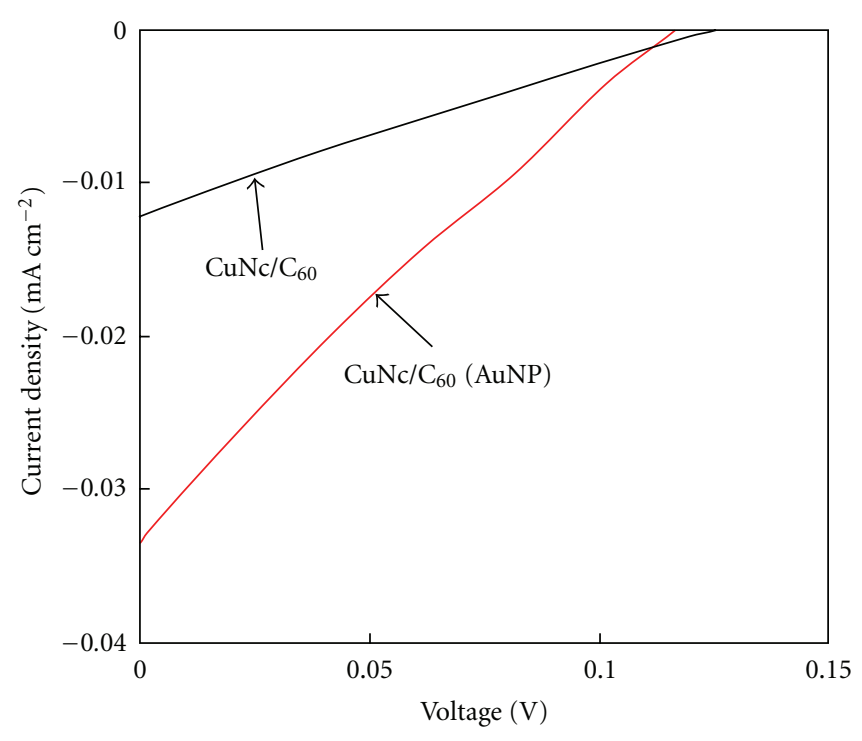

(a)

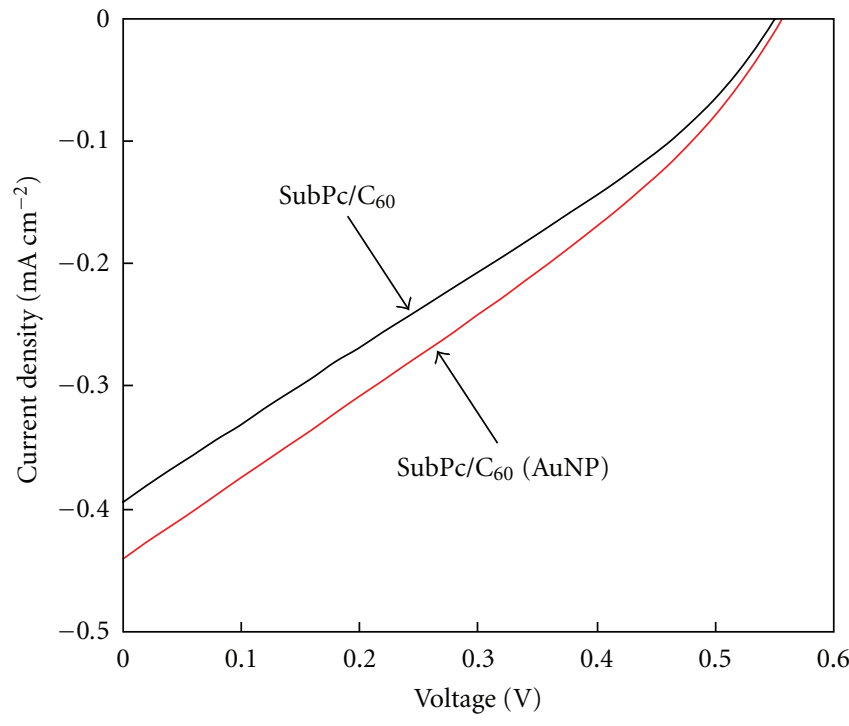

(b)

Figure 6: Measured $J-V$ characteristic of (a) $\mathrm{CuNc}_{6} \mathrm{C}_{60}$ and (b) $\mathrm{SubPc} / \mathrm{C}_{60}$ photovoltaic cells with or without AuNP.

TABLE 1: Experimental parameters of the present photovoltaic cells.

\begin{tabular}{lllcc}
\hline Sample & $J_{\text {sc }} / \mathrm{mA} \mathrm{cm}^{-2}$ & $V_{\text {oc }} / V$ & FF & $\eta / \%$ \\
\hline CuNc & 0.012 & 0.13 & 0.25 & $3.7 \times 10^{-4}$ \\
CuNc (AuNP) & 0.034 & 0.12 & 0.24 & $9.8 \times 10^{-4}$ \\
SubPc & 0.39 & 0.55 & 0.27 & 0.058 \\
SubPc (AuNP) & 0.44 & 0.55 & 0.28 & 0.068 \\
\hline
\end{tabular}

cells would be dependent on grain sizes of AuNPs and film thickness of PEDOT:PSS, and control of the grain sizes and film thickness should be investigated further.

\section{Conclusions}

Organic photovoltaic cells were fabricated by using $\mathrm{C}_{60}$ as n-type semiconductor, and $\mathrm{CuNc}$ and $\mathrm{SubPc}$ as $\mathrm{p}$ type semiconductors, respectively. $J-V$ characteristics were investigated under illumination to confirm the photovoltaic cell performance. $\mathrm{CuNc} / \mathrm{C}_{60}$ heterojunction structure with AuNPs provided photoabsorption in the range of 500 to $700 \mathrm{~nm}$ and provided $\eta$ of $9.8 \times 10^{-4} \%$, FF of $0.24, J_{\mathrm{sc}}$ of $0.034 \mathrm{~mA} \mathrm{~cm}^{-2}$, and $V_{\text {oc }}$ of $0.12 \mathrm{~V}$. The device was based on the SubPc/ $\mathrm{C}_{60}$ heterojunction structure with AuNPs provided $\eta$ of $0.068 \%$, FF of $0.28, J_{\mathrm{sc}}$ of $0.44 \mathrm{~mA} \mathrm{~cm}^{-2}$, and $V_{\text {oc }}$ of $0.55 \mathrm{~V}$. Nanostructures of AuNPs were investigated 


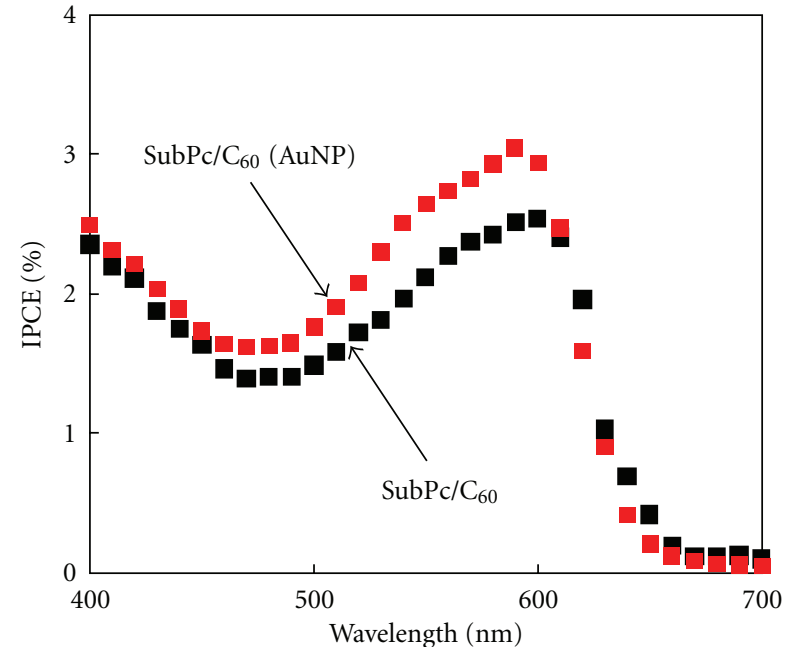

Figure 7: IPCE of SubPc/C 60 photovoltaic cells with or without AuNP.

\begin{tabular}{|c|c|}
\hline & SubPc \\
\hline $\begin{array}{l}\text { Electronic } \\
\text { structure } \\
\text { (LUMO) }\end{array}$ \\
\hline LUMO
\end{tabular}

FIgURE 8: Calculated electronic structures, HOMOs, LUMOs, and energy gaps of CuNc and SubPc.

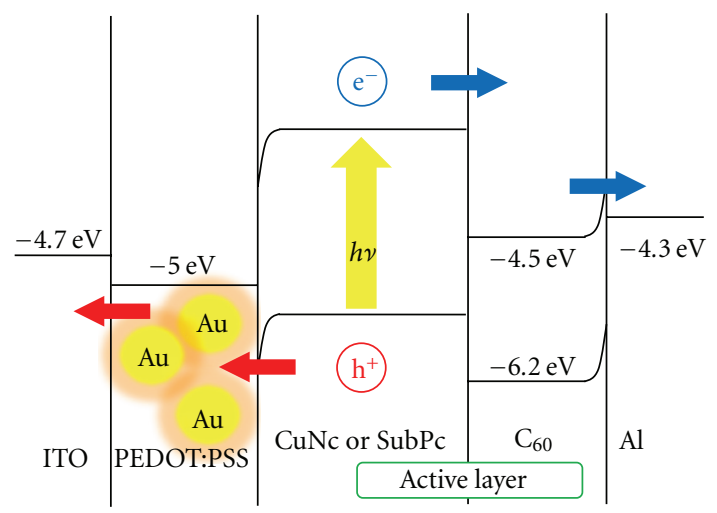

FIGURE 9: Energy level diagram of the present photovoltaic cells. by TEM and X-ray diffraction, and the grain sizes of the AuNPs were determined to be $40 \sim 60 \mathrm{~nm}$. Energy levels of the molecules were calculated by molecular orbital calculations.

\section{References}

[1] M. Moskovits, "Surface-enhanced spectroscopy," Reviews of Modern Physics, vol. 57, no. 3, pp. 783-826, 1985.

[2] K. Kneipp, Y. Wang, H. Kneipp et al., "Single molecule detection using surface-enhanced Raman scattering (SERS)," Physical Review Letters, vol. 78, no. 9, pp. 1667-1670, 1997.

[3] S. Nie and S. R. Emory, "Probing single molecules and single nanoparticles by surface-enhanced Raman scattering," Science, vol. 275, no. 5303, pp. 1102-1106, 1997.

[4] D. M. Schaadt, B. Feng, and E. T. Yu, "Enhanced semiconductor optical absorption via surface plasmon excitation in metal nanoparticles," Applied Physics Letters, vol. 86, no. 6, Article ID 063106, 3 pages, 2005.

[5] W. L. Barnes, A. Dereux, and T. W. Ebbesen, "Surface plasmon subwavelength optics," Nature, vol. 424, no. 6950, pp. 824830, 2003.

[6] J. J. Mock, M. Barbic, D. R. Smith, D. A. Schultz, and S. Schultz, "Shape effects in plasmon resonance of individual colloidal silver nanoparticles," Journal of Chemical Physics, vol. 116, no. 15, pp. 6755-6759, 2002.

[7] P. Royer, J. P. Goudonnet, R. J. Warmack, and T. L. Ferrell, "Substrate effects on surface-plasmon spectra in metal-island films," Physical Review B, vol. 35, no. 8, pp. 3753-3759, 1987.

[8] G. Xu, M. Tazawa, P. Jin, S. Nakao, and K. Yoshimura, "Wavelength tuning of surface plasmon resonance using dielectric layers on silver island films," Applied Physics Letters, vol. 82, no. 22, pp. 3811-3813, 2003.

[9] F. I. Bohrer, A. Sharoni, C. Colesniuc et al., "Gas sensing mechanism in chemiresistive cobalt and metal-free phthalocyanine thin films," Journal of the American Chemical Society, vol. 129, no. 17, pp. 5640-5646, 2007.

[10] H. S. Majumdar, A. Bandyopadhyay, and A. J. Pal, "Datastorage devices based on layer-by-layer self-assembled films of a phthalocyanine derivative," Organic Electronics, vol. 4, no. 1, pp. 39-44, 2003.

[11] H. S. Soliman, A. M. A. El-Barry, N. M. Khosifan, and M. M. El Nahass, "Structural and electrical properties of thermally evaporated cobalt phthalocyanine (CoPc) thin films," EPJ Applied Physics, vol. 37, no. 1, pp. 1-9, 2007.

[12] W. Ma, C. Yang, X. Gong, K. Lee, and A. J. Heeger, "Thermally stable, efficient polymer solar cells with nanoscale control of the interpenetrating network morphology," Advanced Functional Materials, vol. 15, no. 10, pp. 1617-1622, 2005.

[13] M. Granström, K. Petritsch, A. C. Arias, A. Lux, M. R. Andersson, and R. H. Friend, "Laminated fabrication of polymeric photovoltaic diodes," Nature, vol. 395, no. 6699, pp. 257-260, 1998.

[14] M. Glatthaar, M. Riede, N. Keegan et al., "Efficiency limiting factors of organic bulk heterojunction solar cells identified by electrical impedance spectroscopy," Solar Energy Materials and Solar Cells, vol. 91, no. 5, pp. 390-393, 2007.

[15] X. Chen, C. Zhao, L. Rothberg, and M. K. Ng, "Plasmon enhancement of bulk heterojunction organic photovoltaic devices by electrode modification," Applied Physics Letters, vol. 93, no. 12, Article ID 123302, 3 pages, 2008.

[16] F.-C. Chen, J.-L. Wu, C.-L. Lee, Y. Hong, C.-H. Kuo, and M. H. Huang, "Plasmonic-enhanced polymer photovoltaic 
devices incorporating solution-processable metal nanoparticles," Applied Physics Letters, vol. 95, no. 1, Article ID 013305, 2009.

[17] T. Akiyama, K. Aiba, K. Hoashi, M. Wang, K. Sugawa, and S. Yamada, "Enormous enhancement in photocurrent generation using electrochemically fabricated gold nanostructures," Chemical Communications, vol. 46, no. 2, pp. 306-308, 2010.

[18] W. J. Yoon, K. Y. Jung, J. Liu et al., "Plasmon-enhanced optical absorption and photocurrent in organic bulk heterojunction photovoltaic devices using self-assembled layer of silver nanoparticles," Solar Energy Materials and Solar Cells, vol. 94, no. 2, pp. 128-132, 2010.

[19] A. J. Morfa, K. L. Rowlen, T. H. Reilly III, M. J. Romero, and J. van de Lagemaat, "Plasmon-enhanced solar energy conversion in organic bulk heterojunction photovoltaics," Applied Physics Letters, vol. 92, no. 1, Article ID 013504, 3 pages, 2008.

[20] T. Oku, A. Takeda, A. Nagata, T. Noma, A. Suzuki, and K. Kikuchi, "Fabrication and characterization of fullerenebased bulk heterojunction solar cells with porphyrin, $\mathrm{CuInS}_{2}$, diamond and exciton-diffusion blocking layer," Energies, vol. 3, no. 4, pp. 671-685, 2010.

[21] T. Oku, T. Noma, A. Suzuki, K. Kikuchi, and S. Kikuchi, "Fabrication and characterization of fullerene/porphyrin bulk heterojunction solar cells," Journal of Physics and Chemistry of Solids, vol. 71, no. 4, pp. 551-555, 2010.

[22] A. Nagata, T. Oku, K. Kikuchi, A. Suzuki, Y. Yamasaki, and E. Osawa, "Fabrication, nanostructures and electronic properties of nanodiamond-based solar cells," Progress in Natural Science, vol. 20, pp. 38-43, 2010.

[23] M. A. Green, K. Emery, D. L. King, Y. Hishikawa, and W. Warta, "Solar cell efficiency tables (version 28)," Progress in Photovoltaics: Research and Applications, vol. 14, no. 5, pp. 455-461, 2006. 

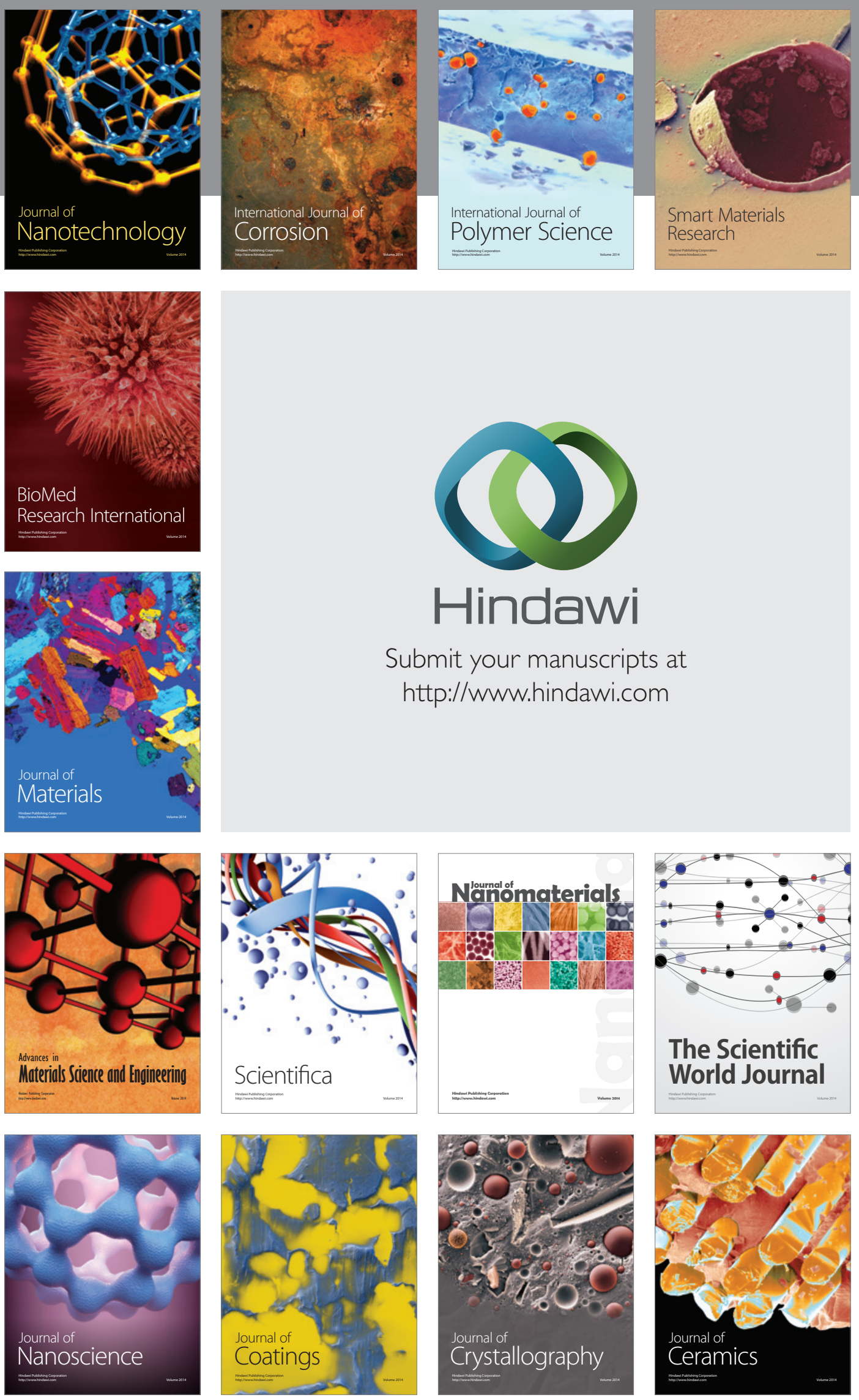

The Scientific World Journal

Submit your manuscripts at

http://www.hindawi.com

\section{World Journal}

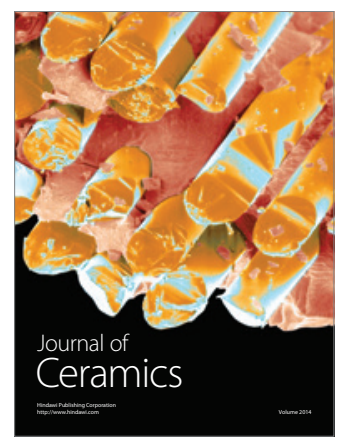

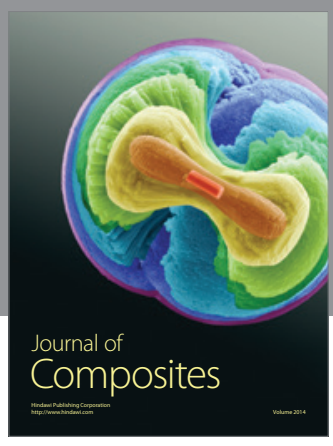
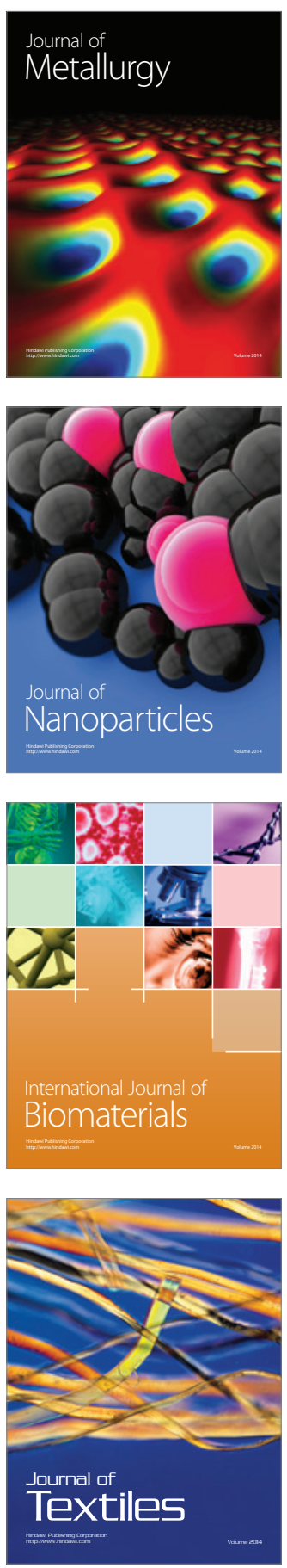